\title{
Correspondence
}

Regional differences in symptomatic fever

\section{management among}

paediatricians in Switzerland:

\section{the results of a}

\section{cross-sectional Web-based}

Dr Mario G. Bianchetti MD, San Giovann Hospital, 6500 Bellinzona, Switzerland.

E-mail:mario.bianchetti@pediatrician.ch

Keywords

acetaminophen, childhood, fever phobia, fever, ibuprofen, paracetamol

Received

4 February 2012

Accepted

23 April 2012

Accepted Article

Published Online

26 April 2012

\section{survey}

Sebastiano A. G. Lava, ${ }^{1,2}$ Giacomo D. Simonetti, ${ }^{2}$

Alessandra Ferrarini, ${ }^{1}$ Gian Paolo Ramelli ${ }^{1} \&$ Mario G. Bianchetti ${ }^{1}$

${ }^{1}$ Department of Pediatrics, Bellinzona and Mendrisio, and University of Bern and ${ }^{2}$ Department of

Pediatric Nephrology, University Children's Hospital Bern and University of Bern, Bern, Switzerland

\section{WHAT IS ALREADY KNOWN ABOUT} THIS SUBJECT

- In children antipyretic drugs should be prescribed to treat the general discomfort that accompanies fever. Nonetheless, a gap often exists between available evidence and clinical practice.

- Fever is often a cause of fear among both parents and health care providers.

- Prescription patterns of several drugs are modulated by socio-cultural factors.

\section{WHAT THIS STUDY ADDS}

-Among the main regions of Switzerland there are significant regional differences in symptomatic fever management as well as in the perceived frequency of fear of fever. - Paediatricians active in the German speaking region less frequently differ from available recommendations than their colleagues active in the French and Italian speaking regions.

\section{AIMS}

In symptomatic fever management, there is often a gap between everyday clinical practice and current evidence. We were interested to see whether the three linguistic regions of Switzerland differ in the management of fever.

\section{METHODS}

A close-ended questionnaire, sent to 900 Swiss paediatricians, was answered by 322 paediatricians. Two hundred and fourteen respondents were active in the German speaking, 78 in the French speaking and 30 in the Italian speaking region.

\section{RESULTS}

Paediatricians from the French and Italian speaking regions identify a lower temperature threshold for initiating a treatment and more frequently reduce it for children with a history of febrile seizures. A reduced general appearance leads more frequently to a lower threshold for treatment in the German speaking than in the French and Italian speaking areas. Among 1.5 and 5 -year-old children the preference for the rectal route is more pronounced in the German than in the French speaking region. French speaking respondents more frequently prescribe ibuprofen and an alternating regimen with two drugs than German speaking respondents. Finally, the stated occurrence of exaggerated fear of fever was higher in the German and Italian speaking regions.

\section{CONCLUSIONS}

Switzerland offers the opportunity to compare three different regions with respect to management of febrile children. This inquiry shows regional differences in symptomatic fever management and in the perceived frequency of exaggerated fear of fever. The gap between available evidence and clinical practice is more pronounced in the French and in the Italian speaking regions than in the German speaking region. 


\section{Introduction}

Fever is frequent in childhood and a very common reason for a child to be taken to the doctor [1]. It is a cause of apprehension for parents, bringing to the surface several fears [2]. Management of fever with antipyretic drugs is widespread. There is some evidence that antipyretic drugs increase the length of viral shedding and length of illness. These drugs may also have a negative impact on bacterial illnesses [2]. By contrast, there is no evidence that fever in itself has any detrimental effects and fears are mostly unfounded, since the outcome of a febrile illness depends upon the underlying condition and there is no proof that reducing fever diminishes mortality or morbidity [2]. Similarly, despite comprehensible concerns about febrile seizures, there is no evidence that antipyretics prevent them from recurring $[2,3]$.

Guidelines on how to manage febrile children initially point out that the primary goal of treating febrile children should be to improve the child's overall comfort rather than focus on the normalization of temperature [4-7].

Many data [4-7], including among others the results of a recent survey among Swiss paediatricians [8], indicate that there is often a gap between evidence-based medicine and everyday clinical practice in fever management. We were interested to see whether the main linguistic regions of Switzerland differ in the management of fever. For this purpose we used the data of the Swiss national survey on symptomatic fever management among Swiss board-certified paediatricians [8].

\section{Methods}

Between June of 2010 and March of 2011, we performed a cross-sectional survey on symptomatic management of fever among the members of the regional societies of Paediatrics from 13 of the 26 Swiss cantons. These paediatricians represent $72 \%$ of the Swiss board-certified paediatricians and the population of the 13 cantons is approximately 6.2 million, which corresponds to $82 \%$ of Switzerland's population. There were 10 German speaking cantons (Aargau, Basel-District, Basel-City, Bern, Glarus, Graubünden, Lucerne, St. Gallen, Thurgau and Zürich), two French speaking cantons (Geneva and Vaud) and one Italian speaking (Ticino) canton [8].

A detailed description of the investigator-initiated, noncommercially sponsored survey, which had been approved by the Swiss-Italian institutional review board, has been recently reported [8]. Briefly, the participants were invited to fill in a close-ended Web-based questionnaire. The questionnaire had been pilot tested for usability and translated from Italian into French and German using the forwardbackward method by professional native translators specialized in medicine.
In an effort to identify potential regional differences, we analyzed the responses to 12 questions that elicited information about the following: (i) rectal temperature threshold to initiate drug management in a 3-year-old child nontoxic in appearance (possible answers: <38.0, 38.0$38.4,38.5-38.9,39.0-39.4$ and $\geq 39.5^{\circ} \mathrm{C}$ ), (ii) role of child's past history of febrile seizures in influencing the temperature threshold to initiate a treatment (never or rarely, sometimes and often important), (iii) role of child's general appearance in influencing the temperature threshold to initiate a treatment (never or rarely, sometimes and often important), (iv) prescription of paracetamol (acetaminophen) as first choice drug in the management of fever (first choice and not first choice); preferred route of administration for paracetamol (rectal and oral route) in an 18-month-old infant, (v), in a 5-year-old child (vi) and in a 10-year old child (vii), (viii) prescription of the non-steroidal anti-inflammatory agent ibuprofen (never or rarely, sometimes and often prescribed) and (ix) role of an alternating regimen with two drugs (e.g. paracetamol and ibuprofen) for fever reduction (never or rarely, sometimes and often prescribed). Finally, questions 10,11 and 12 addressed the occurrence of the exaggerated fear of fever. Question 10 addressed the perceived frequency of the exaggerated fear of fever among parents (never or rarely, sometimes and often present), question 11 the influence of the exaggerated fear of fever on drug management of fever (never or rarely, sometimes and often lower threshold because of parental worries) and question 12 the possibility of educating families about the fear of fever (never or rarely, sometimes and often possible).

Ordered categorical responses to the questionnaire were assigned a numerical score. Numerical data were analyzed using the Kruskal-Wallis test and the BonferroniDunn post hoc procedure. The $\chi^{2}$-test of association was used to analyze proportions. Significance was assumed when $P<0.05$ (two-tailed).

\section{Results}

The questionnaire was answered by 322 (36\%) of the 900 invited paediatricians: 214 out of 601 (36\%) paediatricians answered the German, 78 out of $243(32 \%)$ the French and 30 out of $56(54 \%)$ the Italian version of the questionnaire (Table 1).

The respondents working in the two neo-latin regions (i.e. the Italian and the French speaking one) claimed that they identify a significantly $(P<0.001)$ lower rectal temperature threshold (by $0.5^{\circ} \mathrm{C}$ ) for initiating an antipyretic treatment in a non-toxic appearing child than the respondents of the German speaking region, without significant difference between the French and the Italian speaking regions (Figure 1A). Furthermore, according to the received responses, in all linguistic regions $\geq 54 \%$ of the respondents often reduce the temperature threshold for initiat- 


\section{Table 1}

Characteristics of 322 Swiss board-certified paediatricians, who answered the questionnaire. The female : male ratio and the time since qualification were not statistically different in the three regions

\begin{tabular}{|llll|} 
& $\begin{array}{l}\text { German } \\
\text { speaking } \\
\text { region }\end{array}$ & $\begin{array}{l}\text { French } \\
\text { speaking } \\
\text { region }\end{array}$ & $\begin{array}{l}\text { Italian } \\
\text { speaking } \\
\text { region }\end{array}$ \\
\hline Responding paediatricians & & & \\
$n$ & 214 & 78 & 30 \\
$\%$ & 67 & 24 & 9 \\
Female gender (\%) & 39 & 49 & 43 \\
Medical qualification diploma* (year) & & & \\
$<1965(\%)$ & 3 & 5 & 3 \\
$1965-1974(\%)$ & 26 & 23 & 23 \\
$1975-1984(\%)$ & 26 & 26 & 17 \\
$1985-1994(\%)$ & 22 & 23 & 30 \\
$1995-2004(\%)$ & 19 & 19 & 20 \\
$\geq 2005(\%)$ & 4 & 4 & 7 \\
\hline
\end{tabular}

*Information not available in 14 cases.

ing an antipyretic treatment in children with a past history of febrile seizures (Figure 1B). This attitude is more frequent among paediatricians active in the French $(P<0.001)$ and the Italian speaking $(P<0.01)$ regions than in the German speaking one (without significant difference between the French and the Italian speaking regions). Finally, a reduced general appearance more frequently leads to a lower threshold for initiating an antipyretic treatment in the German speaking region than it does in the French $(P<0.001)$ and Italian speaking $(P<0.001)$ regions, without significant difference between the French and the Italian speaking regions (Figure 1C).

In all regions $\geq 94 \%$ of the respondents stated that they prescribe paracetamol as the first choice antipyretic drug (no significant difference was noted between the three regions). According to the received responses (Figure 2A), in all regions the rectal route of administration is widespread ( $\geq 64 \%$ of the respondents) among 1.5-year-old children, while the oral route strongly predominates among older children ( $\geq 83 \%$ for 5 -year-old and $\geq 99 \%$ for 10 -year-old children). Among 1.5 and 5 -year-old children the preference for the rectal route is more pronounced $(P<0.001)$ in the German than in the French speaking region (without significant differences between the Italian and the German speaking regions as well as between the Italian and the French speaking regions). At the same time (Figure $2 \mathrm{~B}$ ) respondents of the French speaking region more frequently $(P<0.001)$ prescribe ibuprofen than respondents of the German speaking region (no significant difference was noted between the Italian and the French speaking regions as well as between the Italian and the German speaking regions). Similarly (Figure $2 \mathrm{C}$ ), an alternating regimen with two drugs is more frequently prescribed in the French speaking region than in the German $(P<0.001)$ and the Italian speaking $(P<0.001)$ regions (no significant difference was noted between the Italian and the German speaking regions).

The last set of questions addressed the occurrence of the exaggerated fear of fever (Figure 3). Respondents from all the three regions consider that the exaggerated fear of fever is widespread among parents. Nevertheless, the stated occurrence (Figure 3A) was higher in the German(61\% of the respondents state that fear of fever is frequent; $P<0.001)$ and in the Italian speaking $(67 \% ; P<0.001)$ regions than in the French speaking (28\%) region, with no significant difference between the Italian and the German speaking regions. In all linguistic regions $\geq 77 \%$ of the respondents stated that they rarely or never lower the temperature threshold (Figure 3B) for initiating a treatment exclusively in order to calm worried parents (without significant difference between the three linguistic regions). Similarly, in all regions the vast majority of the respondents $(\geq 50 \%)$ think that it is often possible to educate families (Figure 3C) about the fear of fever (without significant difference between the three linguistic regions).

\section{Discussion}

Switzerland offers the unique opportunity to compare three different regions with respect to management of febrile children. The present inquiry shows the existence of significant regional differences in symptomatic fever management and in the perceived frequency of exaggerated fear of fever, which are summarized in Table 2.

Firstly, it is currently recommended that antipyretics should be used only when the fever is associated with evident discomfort [5-7]. The inquiry indicates that the child's general appearance more often modulates the temperature threshold to initiate treatment in the German linguistic region than in the two neo-latin regions. Secondly, use of antipyretics is not effective and therefore not advised for the prevention of febrile seizures [3-7]. Paediatricians practising in the German speaking region less frequently differ from this recommendation than their colleagues from the French and Italian speaking regions. Thirdly, combined or alternating use of antipyretics is discouraged $[4-7,9]$. The inquiry shows that an alternating regimen with two drugs is less frequently prescribed in the German and the Italian speaking regions than in the French speaking region. Finally, it is also recommended that oral administration of paracetamol is preferable to rectal administration [5-7]. French and Italian speaking paediatricians less commonly prescribe rectal paracetamol than their German speaking colleagues. This issue, however, is controversial as recent data suggest that there is no difference between oral and rectal paracetamol [10]. Moreover, many parents prefer the suppositories to oral medication because of ease of administration [10].

These differences, together with the tendency towards a lower rectal temperature threshold for initiating a drug 


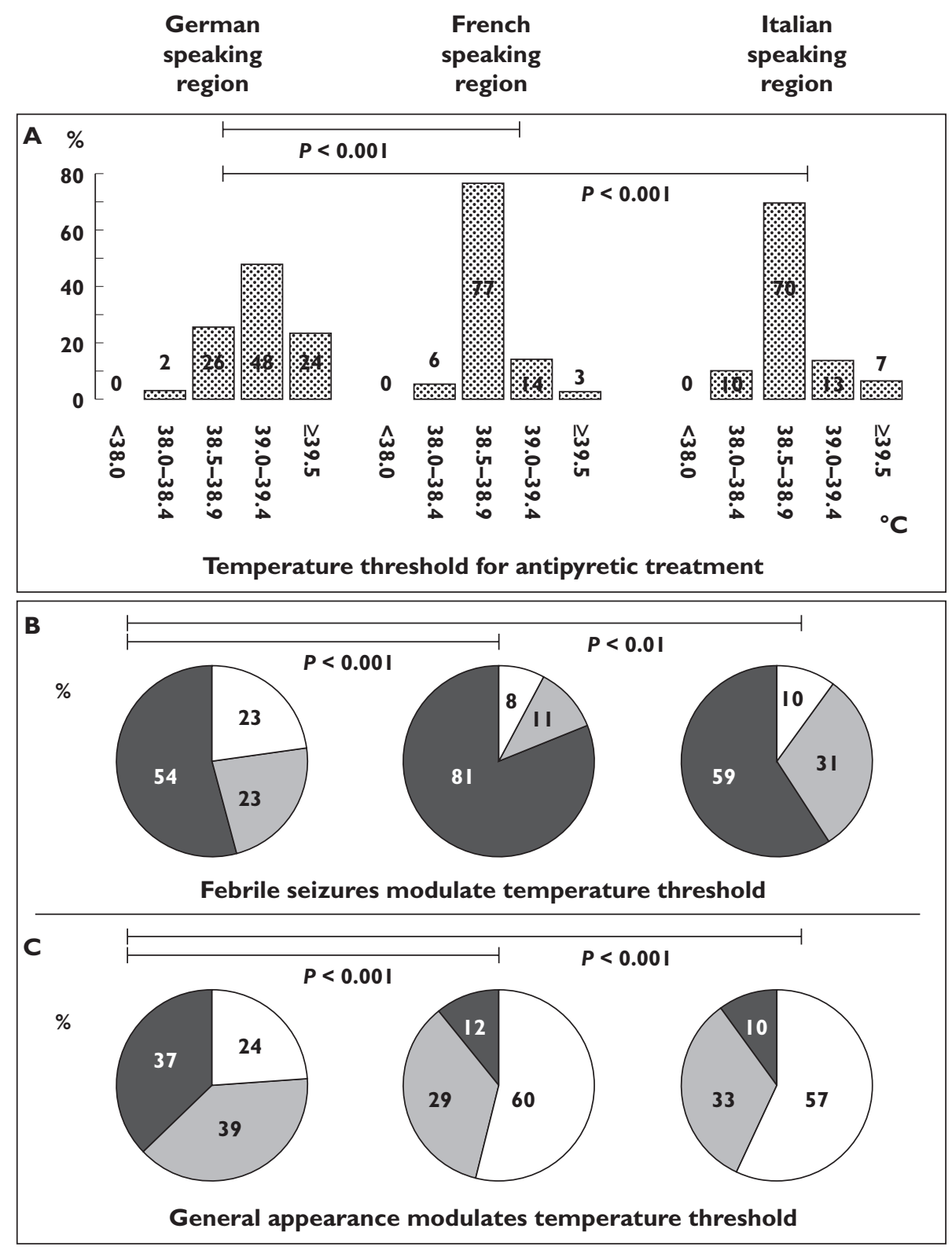

\section{Figure 1}

Regional differences in symptomatic fever management among paediatricians in Switzerland. A) depicts the rectal temperature threshold to initiate drug management in a 3-year-old child, who is nontoxic in appearance. The pie charts depict the role of a past history of febrile seizures (B) and that of the child's general appearance (C) in modulating the temperature threshold to initiate a treatment. $\square$, never-rarely; $\square$, sometimes; $\square$, often

treatment and a more frequent prescription of ibuprofen (either alone or as 'alternating regimen') in the French and, to a less extent, in the Italian speaking regions of Switzerland, are not surprising. Actually, the prescription of antimicrobials and the vaccine coverage levels are higher in the neo-latin regions than in the German speaking region of Switzerland [11-13]. These variations are likely not attributable to the regulation of drug delivery, which is almost identical in the three regions.

Switzerland lies at the intersection of the German, French and Italian socio-cultural influences. Studies per- formed in neighbouring countries show both a higher antimicrobial consumption and a higher vaccine coverage level in France and Italy than in Germany [13-15]. Hence, we feel that in Switzerland differences between the two neo-latin regions and the German speaking region with respect to both symptomatic fever management as well as with respect to antimicrobial prescription and vaccine coverage pertain to socio-cultural issues [16]. Our impression is supported among others by observations from the United States of America, where high levels of anxiety are found among Latino parents with a feverish child [17-19]. 

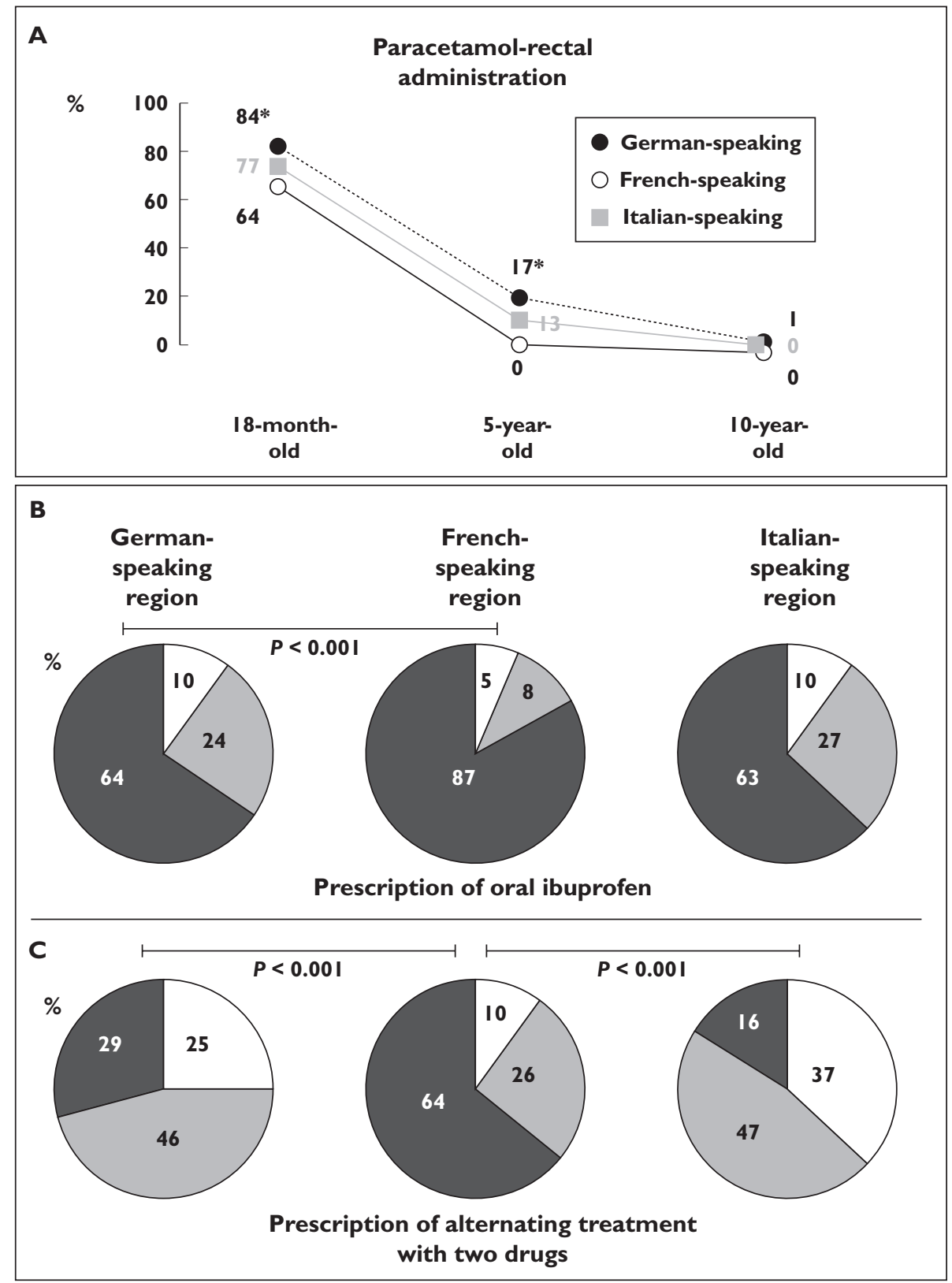

\section{Figure 2}

Regional differences in symptomatic fever management among paediatricians in Switzerland. A) depicts the preferred route of administration for paracetamol in an 18-month-old, in a 5-year-old and in a 10-year-old patient. The symbol * denotes a significant preference $(P<0.001)$ for the rectal route in the German as compared with the French-speaking region. The pie charts illustrate the prescription of the non-steroidal anti-inflammatory agent ibuprofen (B) and that of an alternating regimen (C) with two drugs (mostly paracetamol and ibuprofen). $\square$, never-rarely; $\square$, sometimes; $\square$, often

Furthermore, many of these parents believe that moderate fever can cause serious neurological damage or even death [17-19].

Since 1980 it has been recognized that many parents have several unrealistic fears about fever and the term 'fever phobia' was coined [20]. Since then, a number of studies, including a very recently published Japanese report, have been finding similar levels of worry among caregivers [19-22]. Swiss paediatricians believe that fever phobia is widespread among caregivers. Interestingly, pediatricians working in the German and Italian speaking regions feel that fever phobia is more common than do their colleagues working in the French speaking region. The rather low pervasiveness of fever phobia claimed by respondents from the French speaking region is surprising, considering that the practice of these paediatricians is more dissimilar from available recommendations on fever management than that of paediatricians working in the 


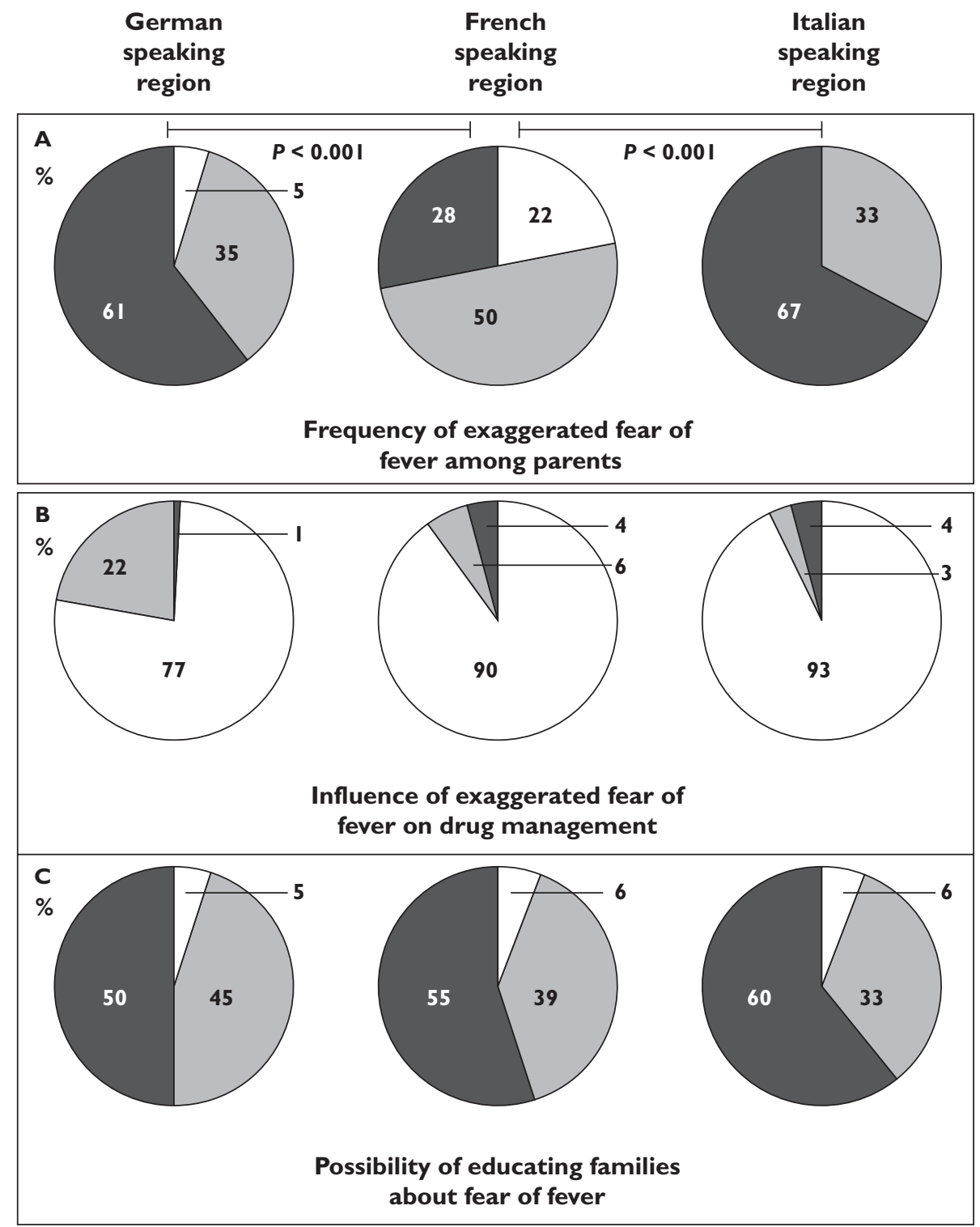

\section{Figure 3}

Regional differences in symptomatic fever management among paediatricians in Switzerland. A) addresses the frequency of exaggerated fear of fever among parents as perceived by the participating paediatricians, B) the influence of exaggerated fear of fever on the temperature threshold to manage fever and C) the potential to educate families about the fear of fever in everyday clinical practice. $\square$, never-rarely; $\square$, sometimes; $\square$, often

German and, to a less extent, Italian speaking regions. We do not have any clear-cut explanation for this intriguing and paradoxical observation. One may speculatively presume that in the French-speaking region of Switzerland aggressive management of fever somehow avoids the symptoms of parental fever phobia. On the other side, the tendency to over-control fever noted in this region of Switzerland suggests that part of the reason for parental fever phobia results from messages conveyed by health care providers $[23,24]$.

Our results must be interpreted in the context of at least four methodological limitations. Firstly, the survey was pilot tested for usability but not validated [25].
Secondly, although self-reported clinical practices by physicians are often used, answers on surveys that ask doctors how they deal with specific conditions sometimes differ from their everyday clinical practice. Thirdly, the $<50 \%$ response rate and the failure to include 13 cantons introduces some biases. It is possible that the survey participants are more directly interested in fever management issues than non-respondents, so that some results might not be generalized to all Swiss paediatricians. Finally, the most important limitation of the study relates to its scope [8]. In this nationwide inquiry, primacy was given to collecting a small amount of quantitative information on fever management from a large number of paediatricians. Thus, 


\section{Table 2}

Regional distinctiveness in symptomatic fever management among German, French and Italian speaking paediatricians in Switzerland

\begin{tabular}{|c|c|c|c|}
\hline & $\begin{array}{l}\text { German } \\
\text { speaking } \\
\text { region }\end{array}$ & $\begin{array}{l}\text { French } \\
\text { speaking } \\
\text { region }\end{array}$ & $\begin{array}{l}\text { Italian } \\
\text { speaking } \\
\text { region }\end{array}$ \\
\hline Temperature threshold for treatment & $\uparrow$ & $\downarrow$ & $\downarrow$ \\
\hline $\begin{array}{l}\text { Febrile seizures modulate temperature } \\
\text { threshold }\end{array}$ & + & H & + \\
\hline $\begin{array}{l}\text { Appearance modulates temperature } \\
\text { threshold }\end{array}$ & H & + & + \\
\hline $\begin{array}{l}\text { Paracetamol first choice antipyretic } \\
\text { drug }\end{array}$ & H & H & + \\
\hline Rectal paracetamol administration & H & + & + \\
\hline Oral ibuprofen & + & H & + \\
\hline Alternate paracetamol and ibuprofen & + & H & + \\
\hline Exaggerated fear of fever frequent & H & + & H \\
\hline Influence of fear on management & $(+)$ & $(+)$ & $(+)$ \\
\hline $\begin{array}{l}\text { Possibility of educating about fear of } \\
\text { fever }\end{array}$ & + & + & ++ \\
\hline
\end{tabular}

The symbol $\uparrow$ denotes a rather high, the symbol $\downarrow$ a rather low temperature threshold. The symbol ++ denotes a common, the symbol $+a$ frequent and the symbol (+) a rare practice.

there is a lack of depth to many aspects of fever management in Switzerland. In particular, there are no data to understand the reasons underlying the regional differences in symptomatic fever management. For this purpose a qualitative study based on in-depth interviews with a small number of participants would be valuable to explore the conception of fever among both physicians as well as families.

In conclusion, rather simplistically, it has been assumed that the skills needed for clinical practice are acquired during medical training and are subsequently sustained by effective continuing medical education. However, clinical practice is a complex phenomenon and changing practice patterns is very challenging [26]. This may be especially true for the management of fever, in which socio-cultural and atavistic issues are of paramount weight [19, 27]. Future research must concentrate on novel intervention approaches that will help improve the translation of current knowledge into every day clinical practice [26]. Actually, educational interventions have been shown to modify parental behaviour with respect to fever [28].

\section{Competing Interests}

There are no competing interests to declare.

The authors would like to thank C. Aebi, G. Berthet, M. Caiata-Zufferey, M. Cavegn, L. Cavegn, S. Fanconi, F. Fiscalini, M. Fontana, R. Ghisla, T.J. Neuhaus, H. Kressebuch, C. Rudin, S. Tschumi and F.H. Sennhauser for their support.

\section{REFERENCES}

1 Nelson DS, Walsh K, Fleisher GR. Spectrum and frequency of pediatric illness presenting to a general community hospital emergency department. Pediatrics 1992; 90: 5-10.

2 Glatstein M, Scolnik D. Fever: to treat or not to treat? World J Pediatr 2008; 4: 245-7.

3 El-Radhi AS, Barry W. Do antipyretics prevent febrile convulsions? Arch Dis Child 2003; 88: 641-2.

4 Eichenwald HF. Fever and antipyresis. Bull World Health Organ 2003; 81: 372-4.

5 Richardson M, Lakhanpaul M, Guideline Development Group and the Technical Team. Assessment and initial management of feverish illness in children younger than 5 years: summary of NICE guidance. BMJ 2007; 334: 1163-4.

6 Chiappini E, Principi N, Longhi R, Tovo PA, Becherucci $P$, Bonsignori F, Esposito S, Festini F, Galli L, Lucchesi B, Mugelli A, de Martino M, Writing Committee of the Italian Pediatric Society Panel for the Management of Fever in Children. Management of fever in children: summary of the Italian Pediatric Society guidelines. Clin Ther 2009; 31: 1826-43.

7 Sullivan JE, Farrar HC, for the Section on Clinical Pharmacology and Therapeutics, Committee on Drugs. Fever and antipyretic use in children. Pediatrics 2011; 127: 580-7.

8 Lava SA, Simonetti GD, Ramelli GP, Tschumi S, Bianchetti MG. Symptomatic management of fever among Swiss board-certified pediatricians: the results of a cross-sectional Web-based survey. Clin Ther 2012; 34: 250-6.

9 Purssell E. Systematic review of studies comparing combined treatment with paracetamol and ibuprofen, with either drug alone. Arch Dis Child 2011; 96: 1175-9.

10 Goldstein LH, Berlin M, Berkovitch M, Kozer E. Effectiveness of oral vs. rectal acetaminophen: a meta-analysis. Arch Pediatr Adolesc Med 2008; 162: 1042-6.

11 Filippini M, Masiero G, Moschetti K. Socioeconomic determinants of regional differences in outpatient antibiotic consumption: evidence from Switzerland. Health Policy 2006; 78: 77-92.

12 Plüss-Suard C, Pannatier A, Kronenberg A, Mühlemann K, Zanetti G. Hospital antibiotic consumption in Switzerland: comparison of a multicultural country with Europe. J Hosp Infect 2011; 79: 166-71.

13 Heymann DL, Fine PE, Griffiths UK, Hall AJ, Mounier-Jack S. Measles eradication: past is prologue. Lancet 2010; 376 : 1719-20.

14 Vander Stichele RH, Elseviers MM, Ferech M, Blot S, Goossens H, European Survaillance of Antibiotic Comsuption (ESAC) Project Group. Hospital consumption of antibiotics in 15 European countries: results of the ESAC Retrospective Data Collection (1997-2002). J Antimicrob Chemother 2006; 58: 159-67.

15 MacKenzie FM, Monnet DL, Gould IM, for the ARPAC Steering Group. Relationship between the number of different 
antibiotics used and the total use of antibiotics in European hospitals. J Antimicrob Chemother 2006; 58: 657-60.

16 Flores G, Rabke-Verani J, Pine W, Sabharwal A. The importance of cultural and linguistic issues in the emergency care of children. Pediatr Emerg Care 2002; 18: 271-84.

17 Crocetti M, Sabath B, Cranmer L, Gubser S, Dooley D. Knowledge and management of fever among Latino parents. Clin Pediatr (Phila) 2009; 48: 183-9.

18 Cohee LM, Crocetti MT, Serwint JR, Sabath B, Kapoor S. Ethnic differences in parental perceptions and management of childhood fever. Clin Pediatr (Phila) 2010; 49: 221-7.

19 Rupe A, Ahlers-Schmidt CR, Wittler R. A comparison of perceptions of fever and fever phobia by ethnicity. Clin Pediatr (Phila) 2010; 49: 172-6. childhood fever. Clin Pediatr (Phila) 2010; 49: 221-7.

20 Schmitt BD. Fever phobia: misconceptions of parents about fevers. Am J Dis Child 1980; 134: 176-81.
21 Purssell E. Fever phobia revisited. Arch Dis Child 2004; 89: 89-90.

22 Sakai R, Okumura A, Marui E, Niijima S, Shimizu T. Does fever phobia cross borders? The case of Japan. Pediatr Int 2012; 54: 39-44.

23 May A, Bauchner H. Fever phobia: the pediatrician's contribution. Pediatrics 1992; 90: 851-4.

24 Kai J. Parents and their child's fever: do as I say, not as I do? Fam Pract 1998; 15: 505-6.

25 Rattray J, Jones MC. Essential elements of questionnaire design and development. J Clin Nurs 2007; 16: 234-43.

26 Flores G, Lee M, Bauchner H, Kastner B. Pediatricians' attitudes, beliefs, and practices regarding clinical practice guidelines: a national survey. Pediatrics 2000; 105: 496-501.

27 Purssell E. Parental fever phobia and its evolutionary correlates. J Clin Nurs 2009; 18: 210-8.

28 Casey R, McMahon F, McCormick MC, Pasquariello PS Jr, Zavod W, King FH Jr. Fever therapy: an educational intervention for parents. Pediatrics 1984; 73: 600-5. 